\title{
Assessment of Low-Cost GPS Receiver Accuracy and Precision in Forest Environments
}

\author{
José R. Rodríguez-Pérez'; M. F. Álvarez²; and Enoc Sanz-Ablanedo³
}

\begin{abstract}
Selecting the appropriate receiver is an issue when a major portion of global positioning system (GPS) data collection is below forest canopies. This study compares four low-cost GPS receivers, in order to determine the most suitable receiver for position assessment under different forest canopy covers, in terms of ease of use, accuracy, and reliability. A total of 33 positional assessments were gathered per receiver, plot, and method, in 18 forest locations. Data were described and analyzed through a sample comparison analysis at $95 \%$ confidence level (Mann-Whitney nonparametric test), in order to determine the existence of differences in accuracy and precision in positioning between receivers. Results showed that there were significant differences between the receivers regarding accuracy and precision measuring coordinates; moreover, accuracies were different depending on the canopy cover and forest characteristics. Therefore, practical recommendations for each case were settled in order to help foresters to select the most suitable receiver. Moreover, key forest variables regarding GPS performance were identified, so that forest environments could be effectively clustered by them.
\end{abstract}

DOI: 10.1061/(ASCE)0733-9453(2007)133:4(159)

CE Database subject headings: Global positioning; Surveys; Forests; Assessments.

\section{Introduction}

Global positional system (GPS) receivers are frequently useful for engineering activities in forest environments related to locating or mapping boundaries to monitor harvesting machinery (McDonald et al. 2002), topography and cadastral forest surveys (Soler et al. 1996; Yoshimura et al. 2002), forest inventory (Evans et al. 1992), resource and special area management (Wing and Kellogg 2004), forest area and perimeter estimations (Tachiki et al. 2005), and geographic information system (GIS) forest applications (Wing and Bettinger 2003).

Recreational GPS receivers are quicker and easier to use for gathering position digitally, compared to other available devices, such as handheld digital range finders (which can measure distances and angles between an operator and an object) or digital total stations. Nevertheless, handheld digital range finders are cheaper, and digital total stations are more accurate and precise (Wing and Kellogg 2004). Moreover, the main concerns of using GPS receivers in forest environments are availability and characteristics of satellite signal under the forest canopy. Branches, trunks, and needles/leaves attenuate, distort, or brake GPS signal in forest stands, so that precision and accuracy in location are

\footnotetext{
${ }^{1}$ Assistant Professor, Univ. of León, ESTIA, Avda. Astorga s/n., 24400 Ponferrada, León, Spain (corresponding author). E-mail: jr.rodriguez@unileon.es

${ }^{2}$ Assistant Professor, Univ. of León, ESTIM, Avda. Astorga s/n., 24400 Ponferrada, León, Spain. E-mail: flor.alvarez@unileon.es

${ }^{3}$ Assistant, Univ. of León, ESTIA, Avda. Astorga s/n., 24400 Ponferrada, León, Spain. E-mail: esana@unileon.es

Note. Discussion open until April 1, 2008. Separate discussions must be submitted for individual papers. To extend the closing date by one month, a written request must be filed with the ASCE Managing Editor. The manuscript for this paper was submitted for review and possible publication on December 14, 2006; approved on March 16, 2007. This paper is part of the Journal of Surveying Engineering, Vol. 133, No. 4, November 1, 2007. ()ASCE, ISSN 0733-9453/2007/4-159-167/\$25.00.
}

markedly lower than in areas with unobstructed sky conditions (Hasegawa and Yoshimura 2003).

Research regarding end-user practical recommendations has focused on determining GPS receiver performance under different forest conditions by comparing receivers (Karsky et al. 2000; Yoshimura and Hasegawa 2003) and positioning methods (Næsset et al. 2000; Næsset and Jonmeister 2002; Hasegawa and Yoshimura 2003; Sawaguchi et al. 2003). Techniques such as differential global positioning system (DGPS) improve precision and accuracy under tree canopies (Hasegawa and Yoshimura 2003; Sawaguchi et al. 2003; Satirapod et al. 2003; Tiberius and Kenselaar 2003) but they are not available for recreational GPS receivers, which are cheaper, easier to use, and require less user training than topographic GPS receivers. Therefore, the main issue regarding recreational GPS receivers has been determining their performance under different forest conditions, and whether the precision and accuracy achieved satisfy mapping and engineering requirements.

Several statistics have been used in previous works to estimate GPS accuracy and precision. On the one hand, Sawaguchi et al. (2003) defined the circular error probability (CEP) as a value so that in a circle with a radius equal to $\mathrm{CEP}$ and center equal to the true value, $50 \%$ of the data fall within the circle and the other $50 \%$ lie outside. CEP was used to compare performances in different forest type, antenna height, and season, and to clarify the relationship between sampling number and the convergence of positioning precision. On the other hand, Yoshimura and Hasegawa (2003) used the root-mean-square (RMS) error to test horizontal and vertical GPS positional errors at different locations in forested areas. The distance root-mean-square (DRMS) error was the statistic also proposed to calculate accuracy in the standard positioning service (SPS) (Kaplan 1996), and the estimated positional error (EPE) (defined as the double of DRMS (2DMR) (Dana 1999) was used to compare GPS receivers under forest canopies (Karsky et al. 2000).

Nevertheless, end users dealing with engineering tasks which involve GPS use in forest environments also require information 
Table 1. Forest Characterization for 18 Sampled Stands regarding Stand Density (SDe), Assman Dominant Height $\left(H_{0}\right)$, Hart-Becking Index (HBI), and Canopy Closure

\begin{tabular}{|c|c|c|c|c|c|}
\hline Point & Species & $\begin{array}{c}\text { SDe } \\
\text { (stems/ha) }\end{array}$ & $\begin{array}{l}H_{0} \\
(\mathrm{~m})\end{array}$ & $\begin{array}{l}\mathrm{HBI} \\
(\%)\end{array}$ & Canopy \\
\hline 1 & Pinus radiata & 2,990 & 18.27 & 10.78 & Closed \\
\hline 2 & Pinus radiata & 1,463 & 16.37 & 15.94 & Closed \\
\hline 3 & Pinus sylvestris & 572 & 19.93 & 28.15 & Small gap \\
\hline 4 & Pinus sylvestris & 443 & 18.17 & 28.12 & Small gap \\
\hline 5 & Pinus sylvestris & 507 & 19.27 & 24.75 & Small gap \\
\hline 6 & Pinus sylvestris & 381 & 18.03 & 28.40 & Small gap \\
\hline 7 & Pinus radiata & 2,069 & 18.13 & 12.13 & Closed \\
\hline 8 & Pinus radiata & 3,787 & 17.13 & 10.22 & Closed \\
\hline 9 & Pinus sylvestris & 2,831 & 5.80 & 45.00 & Closed \\
\hline 10 & Pinus radiata & 2,131 & 20.57 & 10.55 & Closed \\
\hline 11 & Pinus radiata & 1,177 & 9.67 & 30.09 & Large gap \\
\hline 12 & Pinus radiata & 1,846 & 10.83 & 21.51 & Closed \\
\hline 13 & Pinus radiata & 1,527 & 11.3 & 22.65 & Small gap \\
\hline 14 & Pinus radiata & 2,196 & 7.67 & 27.77 & Large gap \\
\hline 15 & Pinus radiata & 1,464 & 3.67 & 71.12 & Treeless \\
\hline 16 & Pinus radiata & 1,527 & 7.53 & 34.00 & Large gap \\
\hline 17 & Pinus radiata & 1,464 & 3.67 & 71.12 & Treeless \\
\hline 18 & Pinus radiata & 1,559 & 13.13 & 19.27 & Closed \\
\hline
\end{tabular}

about critical forests variables, which differentiate forest conditions regarding significant differences in GPS response and performance. Previous studies did not find a unique forest variable univocally related to signal performance (Næsset 1999) and some variables (e.g., wood water content) are not operational for a quick accuracy assessment (Sawaguchi et al. 2005).

Therefore, the main goal of this study is to assess and compare accuracy and precision among four different GPS receivers in different forest conditions, as an aid for end-users decision making. Moreover, it is aimed to identify operational forest variables which allow for distinguishing critical forest conditions regarding GPS performance.

\section{Materials and Methods}

\section{Study Area}

The study area was located in the West of León Province (NW Spain), at a latitude of $42^{\circ} 41^{\prime} 50.6^{\prime \prime}-42^{\circ} 43^{\prime} 4.9^{\prime \prime} \mathrm{N}$, and a longitude of $6^{\circ} 37^{\prime} 10.0^{\prime \prime}-6^{\circ} 39^{\prime} 24.9^{\prime \prime} \mathrm{W}$ (WGS-84 Datum); the geodetic height ranged from 824 to $1,082 \mathrm{~m}$.

\section{Materials}

The dataset consisted of 18 points under different tree canopies (Table 1) and one point belonging to the Spanish Geodetic Frame without sky obstructions, in order to test satellite availably during field GPS data collection. Each site consisted of a circular plot (10 $\mathrm{m}$ radius), as homogeneous as possible, and representative of the forest stand conditions.

Sites were characterized regarding canopy cover by calculating two stand variables: stand density (SDe) and Hart-Becking index (HBI). Both variables are sensitive to changes in canopy cover and forest conditions (Avery and Burkhart 2002), so that stands are a priori likely to be stratified according to those variables, in order to test the influence of forest conditions in a GPS signal. SDe was defined as the number of stems per hectare, while HBI characterizes canopy conditions regarding stand density by using average spacing $(a)$ and Assmann dominant height $\left(H_{0}\right)$ [Eq. (1)], representing the tangent of the angle defined by the stem and the line from the top of the tree to the base of another tree, which is the average spacing between the trees (Avery and Burkhart 2002). $H_{0}$ was calculated as the mean height of the 100 largest trees per hectare (three largest trees per plot) (Diéguez Aranda et al. 2003). HBI was selected as a possible critical forest variable because ideally it should be applicable to any kind of stand, even aged or uneven aged, single, or mixed species (West 1983), as opposed to other stand density indices (e.g., SDe). High values usually indicate young and dense stands, while low values are characteristic for older and sparse stands

$$
\operatorname{HBI}(\%)=\frac{a}{H_{0}} \cdot 100=\frac{10000}{\sqrt{\mathrm{SDe}} \cdot H_{0}}
$$

Four receivers were tested in this work: GPS 12XL, eTrex, eTrex Summit, and Geko 201. Each receiver was manufactured by GARMIN and has 12 receiver channels. Technical specifications were different regarding shape, size, and weight. Nominal position accuracy is $15 \mathrm{~m}$ (RMS) for GPS 12XL and eTrex, and below 15 m (RMS) for eTrex Summit and Geko 201. eTrex Summit has an electronic compass and a barometric altimeter built-in. Geko 201 adds wide area augmentation service (WAAS)/ European geostationary navigation overlay system (EGNOS) capability with a nominal accuracy of $3 \mathrm{~m}$. True positions were determined by using a surveying receiver Topcon Hiper+ with a nominal position accuracy of $10 \mathrm{~mm}+1.0 \mathrm{ppm}$.

\section{Methods}

The same test procedure was applied for all sites, days, and receivers. The true position of each tested point was measured by the dual-frequency GPS receiver June 26, 2005. Coordinates were computed as an average of 30 fixed positions. The field survey using recreational GPS receivers was conducted for 10 days (September 16, 20, 21, 25, 27, 30, 2005 and October 4, 5, 8, 9, 2005), from 7:00 am to 2:00 $\mathrm{pm}$. Twenty min before data collection, receivers were turned on to ensure that the current almanac was stored (Karsky et al. 2000). GPS positioning was calculated and stored five times per test point, day, and receiver. Therefore, 3,800 data positions were measured and processed in statistical analysis. Receivers were at the plot center and at $1.7 \mathrm{~m}$ above ground level when positions were measured. No external antennas were used because the aim was to test receivers in the simplest conditions, to achieve operational results. WGS-84 was selected as the datum in all receivers.

Regarding accuracy, horizontal and vertical accuracies were calculated for each sample by the equations

$$
\begin{gathered}
\sigma_{H_{-} \text {acc }}=\sqrt{\left(\bar{E}-E_{\text {true }}\right)^{2}+\left(\bar{N}-N_{\text {true }}\right)^{2}} \\
\sigma_{V_{-} \text {acc }}=\left|\bar{V}-V_{\text {true }}\right|
\end{gathered}
$$

where $\sigma_{H_{-} \text {acc }}$ and $\sigma_{V_{-} \text {acc }}=$ horizontal and vertical accuracy, respectively; $E_{\text {true }}, N_{\text {true }}$, and $V_{\text {true }}=$ true positions along the easting, northing, and vertical directions, respectively.

RMS was calculated to estimate GPS positional error in terms of precision, as a measure of total error defined as the square root of the sum of the variance. Horizontal precision $\left(\sigma_{H_{-} \text {pre }}\right)$ represents the standard deviation of easting and northing measurements, and it was computed as the quadratic component of 
Table 2. Results of Kolmogorov-Smirnov, and Shapiro-Wilk Normality Tests

\begin{tabular}{lcccc}
\hline Normality test & $\sigma_{H_{-} \text {pre }}$ & $\sigma_{H_{\_} \text {acc }}$ & $\sigma_{V_{-} \text {pre }}$ & $\sigma_{V_{-} \text {acc }}$ \\
\hline & (a) Kolmogorov-Smirnov & & \\
\hline Statistic & 0.452 & 0.184 & 0.308 & 0.097 \\
Degrees on freedom & 702 & 702 & 558 & 558 \\
Sig. & 0.000 & 0.000 & 0.000 & 0.000 \\
\hline \multicolumn{5}{c}{ (b) Shapiro-Wilk } \\
\hline Statistic & 0.092 & 0.624 & 0.428 & 0.892 \\
Degrees on freedom & 702 & 702 & 558 & 558 \\
Sig. & 0.000 & 0.000 & 0.000 & 0.000 \\
\hline
\end{tabular}

standard deviation for easting $\left(\sigma_{E}\right)$ and for northing $\left(\sigma_{N}\right)$ directions [Eqs. (4)-(6)]. Moreover, vertical precision was calculated as the standard deviation for vertical measurements [Eq. (7)]

$$
\begin{gathered}
\sigma_{H_{-} \mathrm{pre}}=\sqrt{\sigma_{E}^{2}+\sigma_{N}^{2}} \\
\sigma_{E}=\sqrt{\frac{\sum_{i=1}^{n}\left(E_{i}-\bar{E}\right)^{2}}{n-1}} \\
\sigma_{N}=\sqrt{\frac{\sum_{i=1}^{n}\left(N_{i}-\bar{N}\right)^{2}}{n-1}} \\
\sigma_{V_{-} \mathrm{pre}}=\sqrt{\frac{\sum_{i=1}^{n}\left(V_{i}-\bar{V}\right)^{2}}{n-1}}
\end{gathered}
$$

where $n=$ total number of epochs; $E_{i}$ and $N_{i}=$ location of $i$ th epoch along easting and northing directions, respectively; $\bar{E}$ and $\bar{N}=$ sample mean of the measurements along easting and northing directions, respectively; $V_{i}=$ vertical location of $i$ th epoch; and $\bar{V}=$ sample mean of the vertical measurements.

Data were analyzed through a sample comparison analysis at 95\% confidence level, in order to validate the following null hypothesis: (1) all receivers have the same accuracy $\left(\sigma_{H \text { acc }}\right)$ and precision $\left(\sigma_{H_{-} \text {pre }}\right)$ at measuring horizontal coordinates; $(2)$ all receivers have the same accuracy $\left(\sigma_{V_{-} \text {acc }}\right)$ and precision $\left(\sigma_{V_{\text {_p pre }}}\right)$ at determining altitudes; (3) accuracy and precision $\left(\sigma_{H_{-} \text {acc }}, \sigma_{H_{-} \text {pre }}\right.$, $\left.\sigma_{V_{-} \text {acc }}, \sigma_{V_{-} \text {pre }}\right)$ do not depend on characteristics of forest canopy; and (4) differences in accuracy and precision $\left(\sigma_{H \text { acc }}, \sigma_{H_{\text {pre }}}\right.$, $\left.\sigma_{V \text { acc }}, \sigma_{V \text { pre }}\right)$ between receivers are independent of forest canopy characteristics. Therefore, the Kolmogorov-Smirnov and Shapiro-Wilk normality tests were performed, at $95 \%$ confidence level, to determine if the four variables were normally distributed, as a previous step to select the most appropriate method to compare the different groups. A significant test meant the fit was poor and therefore data were not normal.

If data were normally distributed but variances were not assumed to be equal, the Dunnett's C was calculated to test the null hypothesis that the means were equal when comparing the different groups (Norušis 2005). Otherwise, when the mean was not a representative statistic for the sample, nonparametric tests were more suitable to compare groups. The nonparametric MannWhitney test of location for two independent samples was carried out to determine whether the values of a particular variable differed between two groups. This test does not assume normality in data and can be used regardless of data distribution. Each twotailed significance value estimates the probability of obtaining a $Z$ statistic more extreme (in absolute value) than the one displayed, if there truly is the null hypothesis that the two groups come from the same population. For those groups significantly different according to the Dunnett or Mann-Whitney tests, the error bars with the confidence intervals at $95 \%$ for the individual variables were plotted, as an aid to interpret the tests results.

\section{Results}

\section{Normality Tests}

The Kolmogorov-Smirnov and Shapiro-Wilk normality tests showed that the four variables considered $\left(\sigma_{H_{-} \text {acc }}, \sigma_{H_{-} \text {pre }}, \sigma_{V_{-} \text {acc }}\right.$, $\left.\sigma_{H_{-} \text {pre }}\right)$ were not normally distributed (Table 2$)$. Therefore, the Mann-Whitney nonparametric test was used to test the null hypothesis.

\section{Measuring Horizontal Coordinates and Altitude: Accuracy and Precision}

Table 3 shows the results of testing the null hypothesis that all receivers have the same accuracy and precision at measuring hori-

\begin{tabular}{|c|c|c|c|c|c|c|c|c|c|c|}
\hline \multirow[b]{2}{*}{$\underline{\text { Statistic }}$} & \multicolumn{2}{|c|}{ eTrex } & \multicolumn{4}{|c|}{ eTrex Summit } & \multicolumn{4}{|c|}{ Geko 201} \\
\hline & $\sigma_{H_{\text {_pre }}}$ & $\sigma_{H_{-} \text {acc }}$ & $\sigma_{H_{\text {_pre }}}$ & $\sigma_{H_{-} \text {acc }}$ & $\sigma_{V_{-} \text {pre }}$ & $\sigma_{V_{-} \text {acc }}$ & $\sigma_{H_{\text {_pre }}}$ & $\sigma_{H_{-} \text {acc }}$ & $\sigma_{V_{-} \text {pre }}$ & $\sigma_{V_{-} \text {acc }}$ \\
\hline \multicolumn{11}{|c|}{ (a) $12 \mathrm{XL}$} \\
\hline$U$ & 12,649 & 8,337 & 10,164 & 12,009 & - & - & 12,256 & 13,511 & - & - \\
\hline Sig. & 0.005 & 0.000 & 0.000 & 0.000 & - & - & 0.001 & 0.057 & - & - \\
\hline \multicolumn{11}{|c|}{ (b) eTrex } \\
\hline$U$ & - & - & 12,926 & 10,836 & 12,537 & 14,750 & 13,967 & 10,285 & 7,517 & 17,158 \\
\hline Sig. & - & - & 0.007 & 0.000 & 0.000 & 0.014 & 0.111 & 0.000 & 0.000 & 0.893 \\
\hline \multicolumn{11}{|c|}{ (c) eTrex Summit } \\
\hline$U$ & - & - & - & - & - & - & 15,385 & 14,143 & 3,942 & 14,859 \\
\hline Sig. & - & - & - & - & - & - & 0.914 & 0.159 & 0.000 & 0.019 \\
\hline
\end{tabular}
zontal coordinates $\left(\sigma_{H_{-} \text {acc }}, \sigma_{H_{-} \text {pre }}\right)$ and altitude $\left(\sigma_{V_{-} \text {acc }}, \sigma_{V_{\text {p pre }}}\right)$, by using the Mann-Whitney test ( $U$ statistic). Significance values

Table 3. Result of Mann-Whitney Test ( $U$ Statistic) to Compare Receivers Measuring Horizontal Position and Altitude 

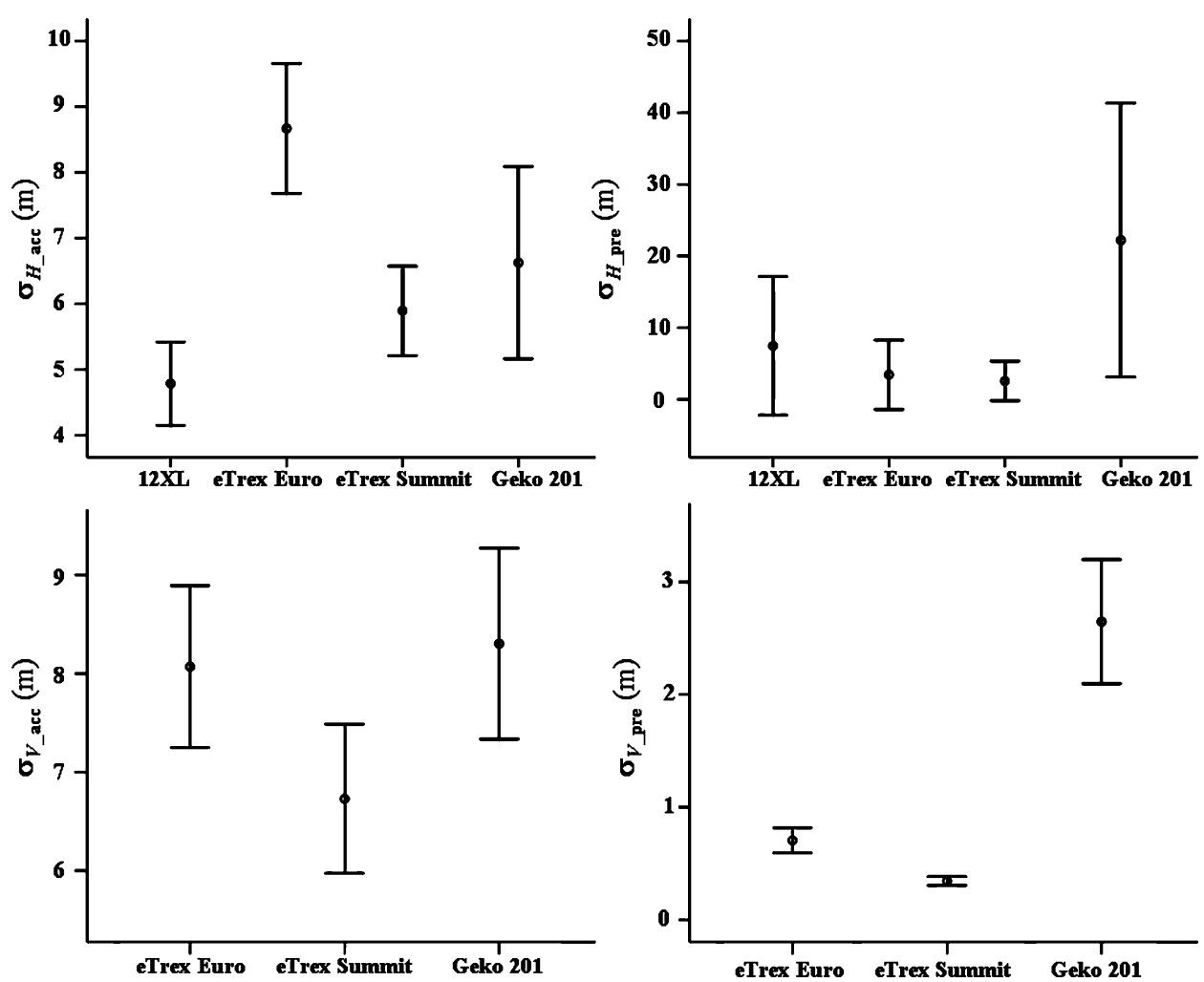

Fig. 1. Error bars with confidence intervals at $95 \%$ for horizontal $\left(\sigma_{H_{-} \text {pre }}\right)$ and vertical $\left(\sigma_{V_{-} \text {pre }}\right)$ precision, and horizontal $\left(\sigma_{H_{-} \text {acc }}\right)$ and vertical $\left(\sigma_{V \text { acc }}\right)$ accuracy, regarding receivers

(Sig.) lower than 0.05 indicated that the null hypothesis, that the two compared groups come from the same population, had to be rejected.

Error bars with the confidence intervals at $95 \%$ for horizontal and vertical precisions and accuracies regarding receivers are shown at Fig. 1. Vertical accuracy and precision were compared among three receivers, because GPS $12 \mathrm{XL}$ does not register altitudes.

Table 3 shows that different $\sigma_{H \text { pre }}$ and $\sigma_{H \text { acc }}$ were achieved depending on the receiver. However, differences in $\sigma_{H_{\text {_p }} \text { pre }}$ were not significant between receivers eTrex and Geko 201, or between eTrex Summit and Geko 201. Horizontal accuracies were different among all receivers but $\sigma_{H_{-} \text {acc }}$ of $12 \mathrm{XL}$ and eTrex Summit were not statistically different than Geko 201. Therefore, and according to Table 3 and Fig. 1, eTrex Summit achieved the best results regarding horizontal precision. With regard to $\sigma_{H \text { acc }}$ the worst distributions of accuracies were obtained by using receivers eTrex and Geko 201, while GPS 12XL attained the best values.

Vertical accuracy and precision were different depending on the receiver, as shown at Table 3 by the Mann-Whitney test values (Sig. <0.05). There were significant differences regarding vertical precision among all receivers; best results were achieved by using eTrex Summit, which was also significantly better than the other two receivers with regard to vertical accuracy. There were no significant differences between eTrex and Geko 201 for vertical accuracy. eTrex Summit achieved the best results determining altitude (according to Table 3 and Fig. 1) considering both precision and accuracy; this is expected because this model incorporates a barometric altimeter.

In this study Geko 201 showed a high variance in the errors (Fig. 1), which advises against recommending this receiver concerning horizontal precision. This fact could be explained because the Geko 201 incorporates augmentation system capability. It therefore received two different correction signals in the field: one from EGNOS and the other one from WAAS, although in Europe only EGNOS is appropriate. Hence, if the Geko 201 receiver works only using EGNOS, accuracy and precision may improve.

\section{Accuracy and Precision regarding Forest Canopy Characteristics}

The influence of forest canopy characteristics in accuracy and precision (horizontal and vertical) was studied by clustering forest stands with regard to two variables: stand density and HBI, calculated as showed in Eq. (1).

The Mann-Whitney test ( $U$ statistic) was applied to assess the null hypotheses, that all receivers have the same values of $\sigma_{H}$ acc , $\sigma_{H_{-} \text {pre }}, \sigma_{V_{-} \text {acc }}$, and $\sigma_{V_{-} \text {pre }}$ at sparse stands $(\mathrm{SDe}<500 \mathrm{stems} / \mathrm{ha})$ as at dense stands (SDe $>500$ stems/ha). A similar test was applied to compare stands with $\mathrm{HBI}<20 \%$ and $\mathrm{HBI}>20 \%$ values. $\mathrm{Re}-$ sults are not shown in this paper but $\sigma_{H}$ acc was significantly different for the two types of SDe and $\sigma_{H_{-} \text {acc }}$ and $\sigma_{H_{-} \text {pre }}, \sigma_{V \text { acc }}$ were significantly different for the two types of HBI tested.

\section{Accuracy and Precision regarding Forest Canopy Characteristics and GPS Receivers}

The previous subsections showed that accuracy and precision for horizontal coordinates and altitude were different depending on receivers and forest canopy characteristics. Moreover, it was aimed to test differences combining both factors, and determine whether differences between receivers depend on forest canopy characteristics.

Table 4 shows the results of performing the Mann-Whitney 
Table 4. Results of Mann-Whitney Test ( $U$ Statistic) regarding Receivers' Accuracy and Precision at Sparse [Stand Density (SDe) $<500$ Stems/ha] and Dense (SDe $>500$ Stems/ha) Stands

\begin{tabular}{|c|c|c|c|c|c|c|c|c|c|c|}
\hline \multirow[b]{2}{*}{ Statistic } & \multicolumn{2}{|c|}{ eTrex } & \multicolumn{4}{|c|}{ eTrex Summit } & \multicolumn{4}{|c|}{ Geko 201} \\
\hline & $\sigma_{H_{-} \text {pre }}$ & $\sigma_{H_{-} \text {acc }}$ & $\sigma_{H_{-} \text {pre }}$ & $\sigma_{H_{-} \text {acc }}$ & $\sigma_{V-\text { pre }}$ & $\sigma_{V_{-} \text {acc }}$ & $\sigma_{H_{-} \text {pre }}$ & $\sigma_{H_{-} \text {acc }}$ & $\sigma_{V_{-} \text {pre }}$ & $\sigma_{V_{-} \text {acc }}$ \\
\hline \multicolumn{11}{|c|}{ (a) Sparse stands [stand density (SDe) $<500 \mathrm{stems} / \mathrm{ha}$ ] } \\
\hline \multicolumn{11}{|l|}{$12 \mathrm{XL}$} \\
\hline$U$ & 1,808 & 1,666 & 1,780 & 1,918 & - & - & 1,996 & 2,001 & - & - \\
\hline $\begin{array}{l}\text { Sig. } \\
\text { eTrex }\end{array}$ & 0.028 & 0.005 & 0.021 & 0.087 & - & - & 0.168 & 0.177 & - & - \\
\hline$U$ & - & - & 2,239 & 1,992 & 2,187 & 1,842 & 2,306 & 2,015 & 1,056 & 2,075 \\
\hline \multicolumn{11}{|c|}{ eTrex Summit } \\
\hline$U$ & - & - & - & - & - & - & 2,292 & 2,233 & 808 & 1,582 \\
\hline Sig. & - & - & - & - & - & - & 0.932 & 0.731 & 0.000 & 0.001 \\
\hline \multicolumn{11}{|c|}{ (b) Dense stands [stand density (SDe) $>500$ stems $/$ ha] } \\
\hline \multicolumn{11}{|l|}{$12 \mathrm{XL}$} \\
\hline$U$ & 5,920 & 3,056 & 4,368 & 5,250 & - & - & 5,419 & 5,758 & - & - \\
\hline $\begin{array}{l}\text { Sig. } \\
\text { eTrex }\end{array}$ & 0.074 & 0.000 & 0.000 & 0.002 & - & - & 0.006 & 0.036 & - & - \\
\hline$U$ & - & - & 5,433 & 4,249 & 4,188 & 6,089 & 6,041 & 4,144 & 2,882 & 6,531 \\
\hline $\begin{array}{l}\text { Sig. } \\
\text { eTrex Suı }\end{array}$ & hit & - & 0.004 & 0.000 & 0.000 & 0.096 & 0.079 & 0.000 & 0.000 & 0.411 \\
\hline$U$ & - & - & - & - & - & - & 6,884 & 6,557 & 1,161 & 6,575 \\
\hline Sig. & - & - & - & - & - & - & 0.882 & 0.440 & 0.000 & 0.461 \\
\hline
\end{tabular}
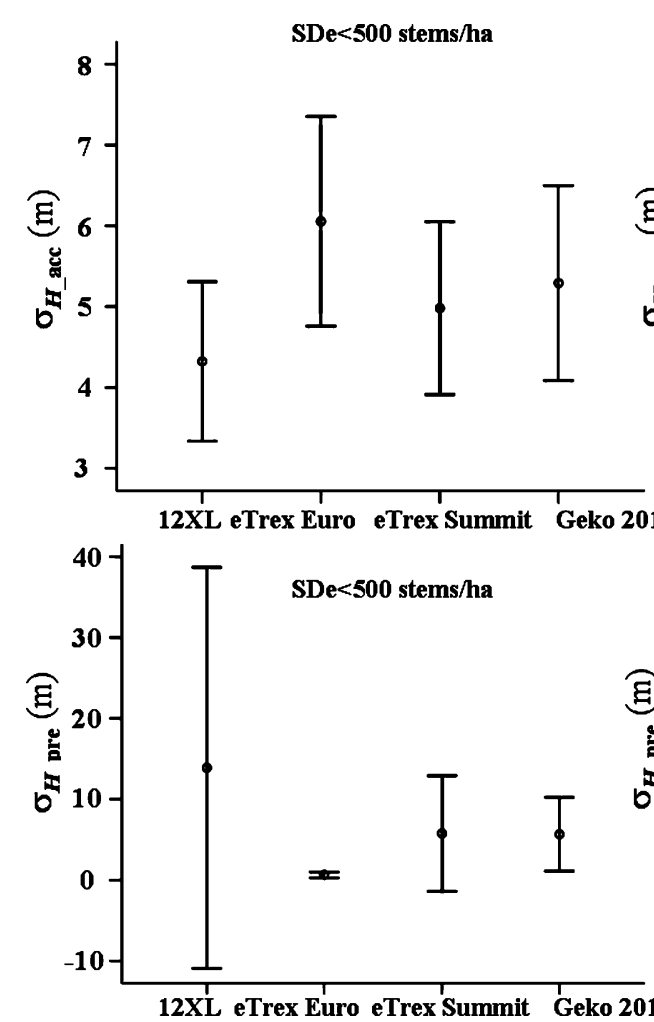

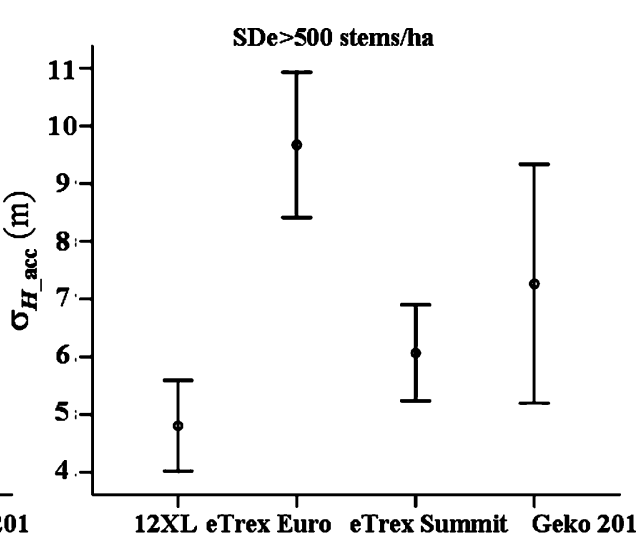

12XL eTrex Euro eTrex Summit Geko 201
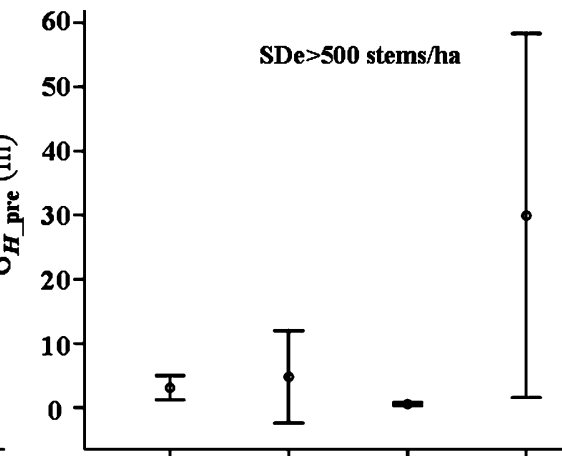

12XI eTrex Euro eTrex Summit Geko 201

Fig. 2. Error bars with confidence intervals at $95 \%$ for horizontal accuracy $\left(\sigma_{H_{-} \text {acc }}\right)$ and precision $\left(\sigma_{H_{-}}\right.$pre $)$, regarding receivers and stand density (SDe) 

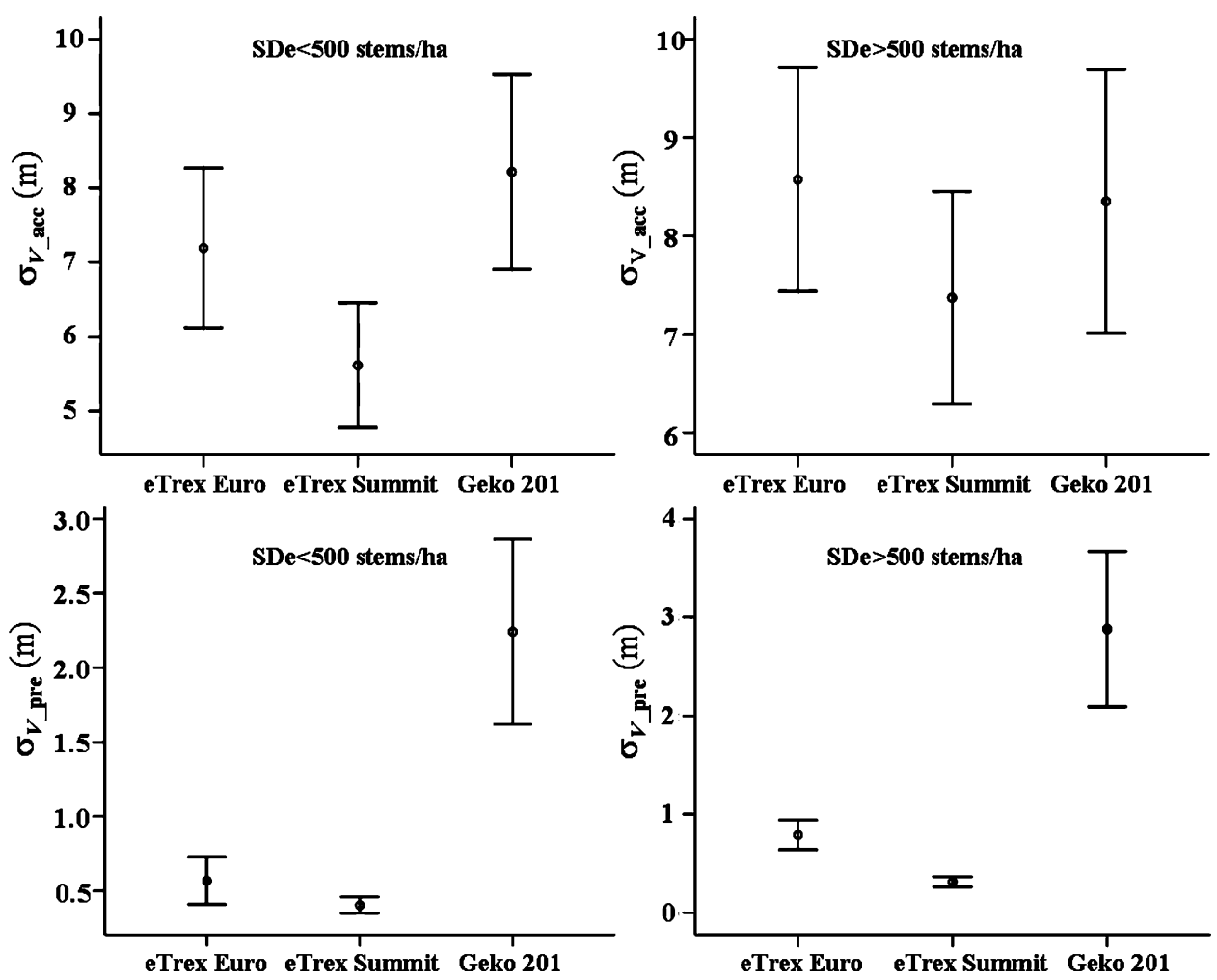

Fig. 3. Error bars with confidence intervals at $95 \%$ for vertical accuracy $\left(\sigma_{V_{-} \text {acc }}\right)$ and precision $\left(\sigma_{V_{-} \text {pre }}\right)$, regarding receivers and stand density (SDe)

test to compare $\sigma_{H_{-} \text {acc }}, \sigma_{H_{-} \text {pre }}, \sigma_{V_{\text {acc }}}$, and $\sigma_{V_{-} \text {pre }}$ for the GPS receivers tested at sparse (SDe $<500$ stems $/ \mathrm{ha})$ and dense (SDe $>500$ stems/ha) stands. Error bars with the confidence intervals at $95 \%$ for $\sigma_{H_{-} \text {acc }}$ and $\sigma_{H_{-} \text {pre }}$ with regard stand density and receivers are shown in Fig. 2. Results for $\sigma_{V_{-} \text {acc }}$ and $\sigma_{V_{-} \text {pre }}$ are shown in Fig. 3.

According to Table 4 and Fig. 2, there were significant differences in horizontal accuracy between receivers $12 \mathrm{XL}$ and eTrex in sparse stands, so that $12 \mathrm{XL}$ achieved the most accurate horizontal measures. It would also be feasible to use eTrex Summit and Geko 201 to get an accurate horizontal position. Regarding horizontal precision, 12XL reached the least precise values, and the eTrex receiver was recommended, considering the smaller confidence interval compared to the two other receivers, which are not as precise.

Concerning vertical measurements, eTrex Summit was significantly more accurate than the other receivers, while there were no differences between eTrex Summit and Geko 201 and eTrex regarding precision (Table 4). Nevertheless eTrex Summit is also recommended due to the narrower confidence interval. Therefore eTrex Summit is the best option to measure altitude at sparse stands, considering accuracy and precision (Fig. 3).

At dense stands, the most accurate receiver for horizontal position was $12 \mathrm{XL}$, while the most precise were $12 \mathrm{XL}$ and eTrex Summit (Fig. 2). In addition, the latter showed the narrowest confidence interval. Accuracy among receivers was not significantly different according to a Mann-Whitney $U$ test (Table 4). However, vertical precision was different depending on the receiver, so that the most precise measurements were recorded by eTrex Sum- mit. Therefore this receiver was recommended to determine altitudes in all types of stands regarding stand density (Table 4 and Fig. 3).

Table 5 shows the results of comparing receivers' accuracy and precision $\left(\sigma_{H_{\text {a acc }}}, \sigma_{H_{\mathrm{p}} \mathrm{pre}}, \sigma_{V_{\text {acc }}}, \sigma_{V_{\mathrm{p}} \mathrm{pre}}\right)$ at different stands regarding HBI (20\% as threshold). Significance values (Sig.) lower than 0.05 indicated where the null hypothesis, where the two compared groups come from the same population, had to be rejected. Figs. 4 and 5 show, respectively, error bars (confidence intervals at 95\%) for horizontal and vertical accuracy and precision regarding $\mathrm{HBI}$ and GPS receivers.

According to Table 5 and Fig. 4, eTrex was the least accurate receiver for measuring easting and northing coordinates in stands with a low $\mathrm{HBI}(<20 \%)$, while the other three receivers presented similar accuracies. Regarding horizontal precision, eTrex or eTrex Summit achieved the best values (lowest), similar to 12XL. Geko 201 showed a wide confidence interval, maybe because the WAAS mode was active when measuring several points. There were also significant differences in vertical precision between receivers (Table 5), with eTrex Summit achieving the most precise values (Fig. 5). Nevertheless, the Mann-Whitney test showed the nonexistence of significant differences in vertical accuracy.

At stands with a greater HBI $(>20 \%)$, the most accurate receiver for horizontal position was $12 \mathrm{XL}$; however, this receiver was the least precise and its confidence interval was the widest (Fig. 4). There were no significant differences in horizontal precision among the other receivers. Regarding altitude, the most accurate and precise values were recorded by the eTrex Summit 
Table 5. Results of Mann-Whitney Test regarding Receivers' Accuracy and Precision at Stands Classified regarding Hart-Becking Index (HBI) (20\% as Thresholding Value)

\begin{tabular}{|c|c|c|c|c|c|c|c|c|c|c|}
\hline \multirow[b]{2}{*}{ Statistic } & \multicolumn{2}{|c|}{ eTrex } & \multicolumn{4}{|c|}{ eTrex Summit } & \multicolumn{4}{|c|}{ Geko 201} \\
\hline & $\sigma_{H_{-} \text {pre }}$ & $\sigma_{H_{-} \text {acc }}$ & $\sigma_{H_{-} \text {pre }}$ & $\sigma_{H_{-} \text {acc }}$ & $\sigma_{V_{-} \text {pre }}$ & $\sigma_{V_{-} \text {acc }}$ & $\sigma_{H_{-} \text {pre }}$ & $\sigma_{H_{-} \text {acc }}$ & $\sigma_{V_{-} \text {pre }}$ & $\sigma_{V_{-} \text {acc }}$ \\
\hline \multicolumn{11}{|c|}{ (a) $\mathrm{HBI}<20 \%$} \\
\hline \multicolumn{11}{|l|}{$12 \mathrm{XL}$} \\
\hline$U$ & 1,916 & 1,200 & 1,484 & 1,948 & - & - & 2,007 & 2,037 & - & - \\
\hline $\begin{array}{l}\text { Sig. } \\
\text { eTrex }\end{array}$ & 0.048 & 0.000 & 0.000 & 0.066 & - & - & 0.112 & 0.144 & - & - \\
\hline$U$ & - & - & 1,939 & 1,514 & 1,298 & 2,163 & 2,334 & 1,471 & 1,153 & 2,161 \\
\hline \multicolumn{10}{|c|}{ eTrex Summit } & 0.350 \\
\hline$U$ & - & - & - & - & - & - & 2,183 & 2,304 & 421.50 & 2,348 \\
\hline Sig. & - & - & - & - & - & - & 0.400 & 0.750 & 0.000 & 0.890 \\
\hline \multicolumn{11}{|c|}{ (b) $\mathrm{HBI}>20 \%$} \\
\hline \multicolumn{11}{|l|}{$12 \mathrm{XL}$} \\
\hline$U$ & 5,680 & 3,846 & 4,779 & 5,157 & - & - & 5,468 & 5,760 & - & - \\
\hline $\begin{array}{l}\text { Sig. } \\
\text { eTrex }\end{array}$ & 0.040 & 0.000 & 0.000 & 0.002 & - & - & 0.014 & 0.059 & - & - \\
\hline$U$ & - & - & 5,872 & 5,051 & 5,784 & 5,609 & 6,054 & 5,055 & 2,747 & 6,573 \\
\hline $\begin{array}{l}\text { Sig. } \\
\text { eTrex Su}\end{array}$ & iit & - & 0.060 & 0.001 & 0.034 & 0.017 & 0.126 & 0.001 & 0.000 & 0.601 \\
\hline$U$ & - & - & - & - & - & - & 6,639 & 6,377 & 1,788 & 5,182 \\
\hline Sig. & - & - & - & - & - & - & 0.691 & 0.367 & 0.000 & 0.001 \\
\hline
\end{tabular}
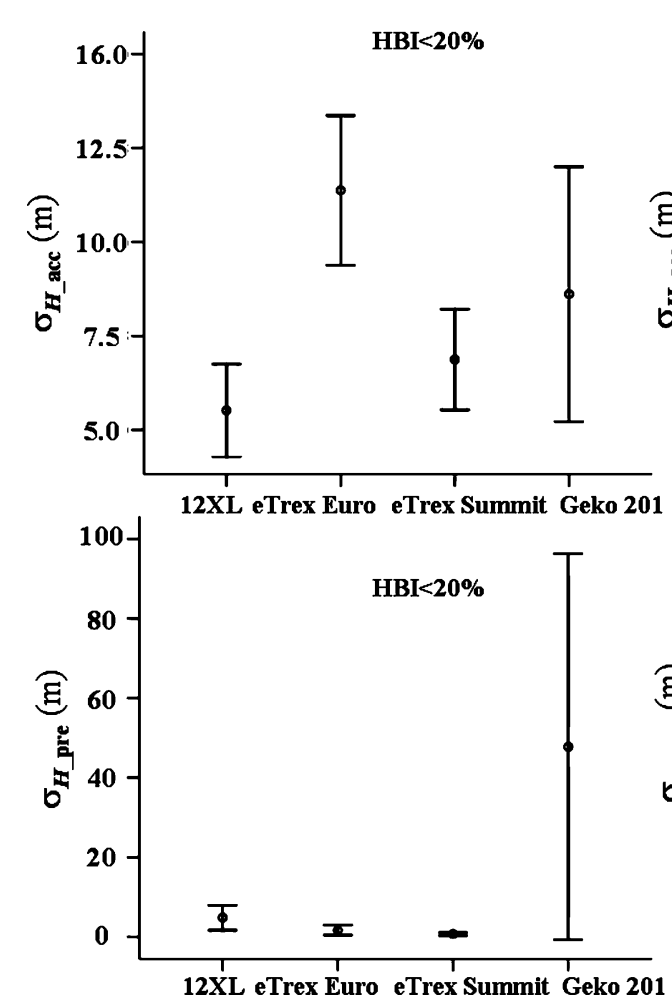

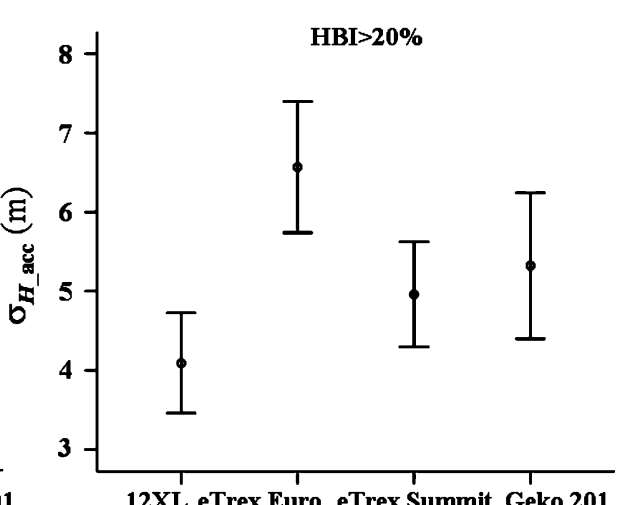

12XL eTrex Euro eTrex Summit Geko 201

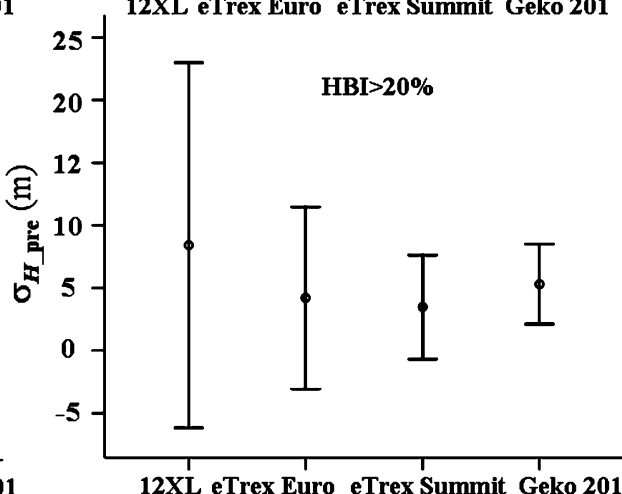

Fig. 4. Error bars with confidence intervals at $95 \%$ for horizontal accuracy $\left(\sigma_{H_{-}}\right.$acc $)$and precision $\left(\sigma_{H_{-} \text {pre }}\right)$, regarding receivers and Hart-Becking index $(\mathrm{HBI})$ 

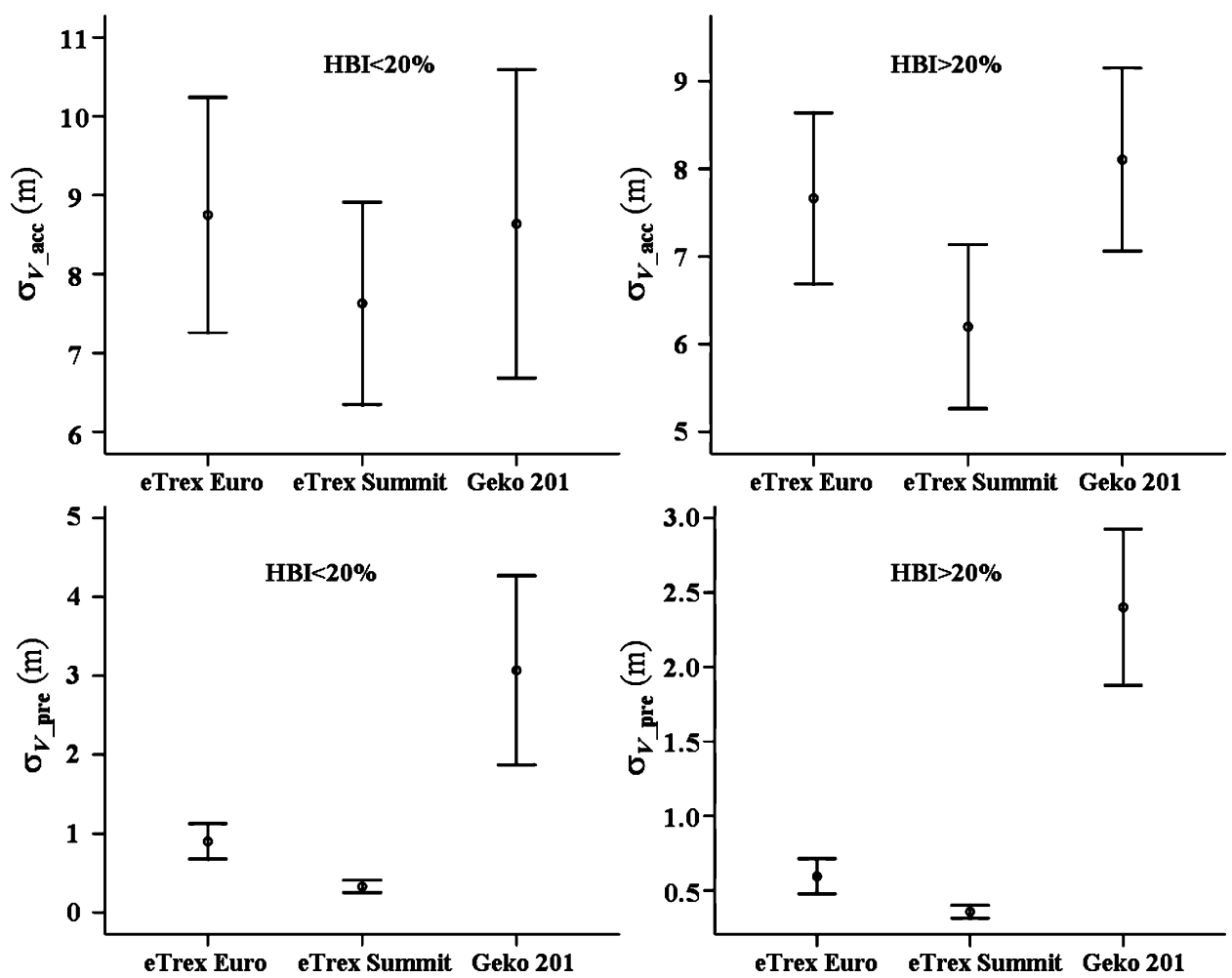

Fig. 5. Error bars with confidence intervals at $95 \%$ for vertical accuracy $\left(\sigma_{V_{-} \text {acc }}\right)$ and precision $\left(\sigma_{V_{-} \text {pre }}\right)$, regarding receivers and Hart-Becking index $(\mathrm{HBI})$

(Fig. 5). Therefore this receiver was recommended to determine altitudes in all types of stands with regard to HBI, as reported when considering stand density.

\section{Discussion}

In this study positional accuracy was affected by stand density due to the lowering of signal-noise ratio and signal interception caused by the electromagnetic waves penetrating through stems and canopies. Those results agree with previous research that related GPS performance and canopy characteristics, as basal area (Næsset 1999, 2001), wood resistance quantity and type of wood material (Sawaguchi et al. 2003), and tree specie and wood water content (Sawaguchi et al. 2005).

Additionally, accuracy and precision were sensitive to HBI, which relates height and average spacing in a forest stand. Previous studies showed that height did not explain horizontal position error either after, during, and before data collection (Næsset 2001; Næsset and Jonmeister 2002), so that using HBI improved forest characterization regarding variables which have an effect on the GPS performance.

Regarding horizontal accuracy, in this study values ranged from 4.80 to $8.80 \mathrm{~m}$, depending on GPS receiver model. Although horizontal accuracies below $1 \mathrm{~m}$ have been reported in previous studies (Næsset et al. 2000; Næsset 2001), these involved using differential postprocessing methods (Næsset 2001; Næsset and Jonmeister 2002) and GPS-GLONASS receivers (Næsset et al. 2000; Næsset 2001), while in this study only lowcost, real-time, hand-held GPS receivers were used, so that neither postprocessing nor long time observations were required. Vertical accuracy ranged from 6.80 to $8.50 \mathrm{~m}$ depending on the
GPS model. This result was similar to the values achieved in other works (Yoshimura and Hasegawa 2003).

Precision for horizontal and vertical positioning was variable and depended on the GPS model and characteristics. This is a general problem using GPS under forest canopies and is solved by increasing the observation time period and applying DGPS (Næsset and Jonmeister 2002; Sawaguchi et al. 2005). Nevertheless, the values achieved are considered precise enough for general applications in forest environments. According to the results, the 12XL was the most accurate receiver, although it was less precise than eTrex models. In order to achieve more precision by using this GPS receiver, we suggest activating the positioning averaging function, so that the receiver will provide more accurate and precise positions.

The eTrex Summit was the most precise for both horizontal and vertical positioning. Because coordinate standard deviation is the most important factor to explain position error (Næsset et al. 2000; Næsset 2001; Næsset and Jonmeister 2002), we recommend using a beacon receiver (which is available for all Garmin receivers) and DGPS mode, in order to improve accuracy under the forest canopy.

The least favorable results were unexpectedly achieved by models eTrex and Geko 201. Therefore, more research is suggested in order to check both receivers' performance. Hence, it is proposed to compare Geko 201's performance when receiving only EGNOS corrections with results when the augmentation system function is turned off.

\section{Conclusions}

This study shows that noticeable differences in accuracy and precision exist for four low-cost GPS receivers tested. SDe and HBI, 
separately or considering both receivers and forest canopy characteristics, drive positional accuracy and precision. If accuracy requirements are moderate-low, tested receivers may provide valuable positional data under the forest canopy as long as careful GPS data acquisition protocols are conducted.

\section{Acknowledgments}

Elements of this project were funded by the University of León through Project No. ULE-2006-1. The writers would like to thank Antonio Gavela for help in field work and the anonymous reviewers whose comments significantly improved this manuscript.

\section{Notation}

The following symbols are used in this paper:

$a=$ average spacing between stands;

$\bar{E}=$ sample mean of measurements along easting;

$E_{i}=$ location of $i$ th epoch along easting;

$E_{\text {true }}=$ true positions along easting;

$H_{0}=$ Assmann dominant height;

$\mathrm{HBI}=$ Hart-Becking index;

$\bar{N}=$ sample mean of measurements along northing;

$N_{i}=$ location of $i$ th epoch along northing;

$N_{\text {true }}=$ true positions along northing;

$n=$ total number of epochs;

$\mathrm{SDe}=$ stand density;

$\bar{V}=$ sample mean of vertical measurements;

$V_{i}=$ vertical location of $i$ th epoch;

$V_{\text {true }}=$ true positions along vertical;

$\sigma_{E}=$ standard deviation along easting;

$\sigma_{H_{\text {a acc }}}=$ horizontal accuracy;

$\sigma_{H_{-} \text {pre }}=$ horizontal precision;

$\sigma_{N}=$ standard deviation along northing;

$\sigma_{V_{-} \text {acc }}=$ vertical accuracy; and

$\sigma_{V_{-} \text {pre }}=$ vertical precision

\section{References}

Avery, T. E., and Burkhart, H. E. (2002). Forest measurements, 5th Ed., McGraw-Hill, New York.

Dana, P. H. (1999). "Global positioning system (GPS) time dissemination for real-time applications." Real-Time Syst., 12(1), 9-40.

Diéguez Aranda, U., Barrio Anta, M., Castedo Dorado, F., Ruiz González, A. D., Álvarez Taboada, M. F., Álvarez González, J. G., and Rojo Alboreca, A. (2003). Dendrometría, Mundi-Prensa, Madrid, Spain.

Evans, D., Carraway, R., and Simmons, G. (1992). "Use of global positioning system (GPS) for forest plot location." Southern J. Applied Forestry, 16(2), 67-70.

Hasegawa, H., and Yoshimura, T. (2003). "Application of dual-frequency GPS receivers for static surveying under tree canopies." J. Forest Research, 8(2), 103-110.

Kaplan, E. D. (1996). Understanding GPS principles and applications, Artech House Inc., Boston.
Karsky, D., Chamberlain, K., Mancebo, S., Patterson, D., and Jasumback, T. (2000). "Comparison of GPS receivers under a forest canopy with selective availability off." USDA Forest Service Project Rep. No. 7100, USDA Forest Service, Missoula, Mont., 〈http://www.fs.fed.us/ eng/pubs/htmlpubs/htm99712318/index.htm $\rangle$ (Nov. 2, 2006).

McDonald, T. P., Carter, E. A., and Taylor, S. E. (2002). "Using the global positioning system to map disturbance patterns of forest harvesting machinery." Canadian J. Forest Research, 32(2), 310-319.

Næsset, E. (1999). "Point accuracy of combined pseudorange and carrier phase differential GPS under forest canopy." Canadian J. Forest Research, 29(5), 547-553.

Næsset, E. (2001). "Effects of differential single- and dual-frequency GPS and GLONASS observations on point accuracy under forest canopies." Photogramm. Eng. Remote Sens., 67(9), 1021-1026.

Næsset, E., Bjerke, T., Øvstedal, O., and Ryan, L. H. (2000). "Contributions of differential GPS and GLONASS observations to point accuracy under forest canopies." Photogramm. Eng. Remote Sens., 66(4), 403-407.

Næsset, E., and Jonmeister, T. (2002). "Assessing point accuracy of DGPS under forest canopy before data acquisition, in the field and after postprocessing." Scandinavian J. Forest Research, 17(4), 351358.

Norušis, M. J. (2005). SPSS 13.0 advanced statistical procedures, Prentice-Hall, Chicago.

Satirapod, C., Wang, J., and Rizos, C. (2003). "Comparing different global positioning system data processing techniques for modeling residual systematic errors." J. Surv. Eng., 129(4), 129-135.

Sawaguchi, I., Nishida, K., Shishiuchi, M., and Tatsukawa, S. (2003). "Positioning precision and sampling number of DGPS under forest canopies." J. Forest Research, 8(2), 133-137.

Sawaguchi, I., Saitoh, Y., and Tatsukawa, S. (2005). "A study of the effects of stems and canopies on the signal to noise ratio of GPS signals." J. Forest Research, 10(5), 395-401.

Soler, T., Álvarez-García, G., Hernández-Navarro, A., and Foote, R. H. (1996). "GPS high accuracy geodetic networks in Mexico." J. Surv. Eng., 122(2), 80-94.

Tachiki, Y., Yoshimura, T., Hasegawa, H., Mita, T., Sakai, T., and Nakamura, F. (2005). "Effects of polyline simplification of dynamic GPS data under forest canopy on area and perimeter estimations." J. Forest Research, 10(6), 419-427.

Tiberius, C., and Kenselaar, F. (2003). "Variance component estimation and precise GPS positioning: Case study." J. Surv. Eng., 129(1), 1118.

West, P. W. (1983). "Comparison of stand density measures in even-aged regrowth eucalypt forest of southern Tasmania." Canadian J. Forest Research, 13(1), 22-31.

Wing, M. G., and Bettinger, P. (2003). "GIS: An updated primer on a powerful management tool." J. For., 101(4), 4-8.

Wing, M. G., and Kellogg, L. D. (2004). "Digital data collection and analysis techniques for forestry applications." Proc., 12th Int. Conf. on Geoinformatics, Univ. of Gävle, Gävle, Sweden, 77-83, 〈http:// www.hig.se/ bjg/geoinformatics/proceedings.html\#77> (September $10,2006)$.

Yoshimura, T., Gandaseca, S., Gumus, S., and Acar, H. (2002). "Evaluating the accuracy of GPS positioning in the forest of the Macka region." Proc., 2nd National Black Sea Forestry Congress, Artrin, Turkey, Vol. 1, 62-69, 〈http://bg66.soc.i.kyoto-u.ac.jp/forestgps/doc/ turkey.pdf $\rangle$ (Nov. 6, 2006).

Yoshimura, T., and Hasegawa, H. (2003). "Comparing the precision and accuracy of GPS positioning in forested areas." J. Forest Research, $8(3), 147-152$. 